\title{
Helicobacter Species are Possible Risk Factors of Cholangiocarcinoma
}

\author{
Soraya J Kaewpitoon ${ }^{1,2,3 *}$, Ryan A Loyd ${ }^{1,3}$, Ratana Rujirakul ${ }^{3}$, Sukij \\ Panpimanmas $^{3,4}$, Likit Matrakool ${ }^{3,4}$, Taweesak Tongtawee ${ }^{3,4}$, Nusorn \\ Kootanavanichpong ${ }^{5}$,Prasit Pengsaa ${ }^{5}$, Ponthip Kompor $^{5}$, Wasugree Chavengkun ${ }^{5}$, \\ Jirawoot Kujapun $^{5}$, Jun Norkaew ${ }^{5}$,Sukanya Ponphimai ${ }^{5}$, Natnapa Padchasuwan ${ }^{6}$, \\ Poowadol Polsripradist ${ }^{7}$, Thawatchai Eksanti ${ }^{8}$, Tanida Phatisena $^{8}$, Natthawut \\ Kaewpitoon ${ }^{2,3,5}$
}

\begin{abstract}
Several infectious agents are considered to be causes of cancer in human, mainly hepatitis $B$ and $C$ viruses, high-risk human pailloma viruses, Helicobacter pylori, Clonorchis sinensis, and Opisthorchis viverrini. Here we described the evident research and the association between Helicobacter spp. and biliary tract cancer particularly cholangiocarcinoma (CCA). Global epidemiological studies have suggested that Helicobacter spp. are possible risk factors for biliary tract diseases. Molecular studies support a linkage of Helicobacter spp. with CCA development. H. pylori, H. bilis, and H. hepaticus, are found in CCA, but the most common species are H.pylori and $\boldsymbol{H}$. bilis. The type of CCA are associated with Helicobacter spp. include extrahepatic CCA, and common bile duct cancer. Up to the present, however, the results from different regions, materials and methods, sub-sites of cancer, and controls have not been consistent, thus introducing heterogeneity. Therefore, a comparison between co-Helicobacter spp.-CCA in the countries with low and high incident of CCA is required to settle the question. Furthermore, clarifying variation in the role of Helicobacter species in this CCA, including pathogenesis of CCA through enhanced biliary cell inflammation and proliferation, is necessary.
\end{abstract}

Keywords: Helicobacter - cholangiocarcinoma - biliary tract cancer - possible risk

Asian Pac J Cancer Prev, 17 (1), 37-44

\section{Introduction}

Infection is one of the main contributors to cancer development particularly the chronic infection mainly hepatitis $\mathrm{B}$ and $\mathrm{C}$ viruses, Helicobacter pylori, Clonorchis sinensis, and Opisthorchis viverrini, the biological agents have been identified as group 1 carcinogens by the International Agency for Research on Cancer Monographs (Oh and Weiderpass, 2014).

Recently, infection with Helicobacter spp. plays a role in the development of various cancer have been reported including biliary tract carcinoma mainly cholangiocarcinoma (CCA). There has been a strong, positive correlation between opisthorchiasis-associated CCA and infection with Helicobacter. Infection with $H$. bilis and $H$. hepaticus species can cause biliary cancer (Chang and Parsonnet, 2010). Recently, Deenonpoe et al (2015) reported liver fluke $O$. viverrini in the biliary tree of the hamsters harbors $H$. pylori and Helicobacterlike bacteria. Accordingly, the association between $O$. viverrini and $H$. pylori may be an obligatory mutualism and possible risk of CCA. Boonyanugomol et al. (2012b; 2012c) reported an association between $H$. pylori and hepatolithiasis or CCA in people in northeast Thailand, a region endemic for opisthorchiasis. Molecular mechanisms integral to $H$. pylori induced hepatobiliary diseases have also been reported (Boonyanugomol et al. 2011; 2012a).

Therefore, update on the association of Helicobactor species and CCA is required, mini-review critically analyzed the literature through the PubMed and Ovid MEDLINE databases searched, using a combination of relevant text words and MeSH terms: Helicobacter and/or cholangiocarcinoma, bile duct neoplasms, intraextrahepatic, common bile duct, gall bladder cancer and biliary tract cancer.

${ }^{1}$ School of Family Medicine and Community Medicine, ${ }^{2}$ Parasitic Disease Research Unit, ${ }^{3}$ Suranaree University of Technology Hospital, ${ }^{4}$ School of Surgery, Suranaree University of Technology, ${ }^{5}$ Faculty of Public Health, Vongchavalitkul University, ${ }^{6}$ Faculty of Public Health, Khon Kaen University, ${ }^{7}$ Provincial Public Health Office of Nakhon Ratchasima, ${ }^{8}$ Nakhon Ratchasima Rajabhat University, Thailand *For correspondence: soraya.k@sut.ac.th 


\section{Cholangiocarcinoma and its Associated Risk Factors}

Cholangiocarcinoma (CCA) a neoplasm that involves epitheial cells of the bile duct, also known as one of the most aggressive malignant tumors associated with local invasiveness and a high rate of metastasis. CCA originated in the bile duct which drained bile from the liver into the small intestine. Other biliary tract cancers include pancreatic cancer, gall bladder cancer, and cancer of the ampulla of Vater. It is also known to be one of the most common causes of cancer related to death in Thailand and it has been reported that Thailand is the highest incident of the world (Green et al., 1991; Sripa et al., 2007; Shin et al., 2010). It has an annual incidence rate of 1-2 cases per 100,000 in the Western world, but rates of CCA have been rising worldwide over the past several decades (Landis et al., 1998; Patel, 2002). This disease is difficult to have early diagnosis, as most symptoms present late in the disease course. In addition, the specific anatomic position can cause periductal extension and result in a very low radical excision rate and a very poor prognosis. Furthermore, CCA is considered to be an incurable and rapidly lethal disease unless all the tumors can be fully resected. Three-year survival rates of $35 \%$ to $50 \%$ are achieved only in a subset of patients who have negative histological margins at the time of surgery (Akamatsu et al., 2011). Survival of CCA patients in northeastern Thailand after supportive treatment was reported and indicated that the stage of disease was an important prognosis factor affecting survival of CCA patients who had diagnosis in late stage. To e encourage patients to see health personnel at early stage is very important (Thunyaharn et al., 2013). Palliative therapeutic approaches, consisting of percutaneous and endoscopic biliary drainage, have usually been used for these patients because there is no effective chemotherapeutic treatment for this type of cancer.

A number of risk factors for the development of CCA have been described and multifactorial is associated to develop CCA. The 3 main factors have been hypothesized, including carcinogenic agents, infection, and other factors. Caroli's disease, choledocal cyst, liver fluke infection, gallstones, hepatolithiasis, sclerosinf cholangitis, thorotrast, and ulcerative colitis, are strongly associated with CCA development. While, asbestos, isoniazid, methyldopa, oral contraceptive, polychlorinated biphenyls are the possible association to the development of CCA (Yeo et al., 1990; Sripa et al., 2005). Infections are associated with the development of CCA, mainly liver flukes, Opisthorchis viverrini (Watanapa and Watanapa, 2002; Sripa et al., 2007; Kaewpitoon et al., 2008; Sripa et al., 2010), O. felineus (Maksimova et al., 2015), Clonorchis sinensis (Hong and Fang, 2012; Rustagi and Dasanu, 2012), and viral hepatitis (e.g. hepatitis B or hepatitis C) (Kobayashi et al., 2000; Lu et al., 2000; Yamamoto et al., 2004). In Thailand, the experimental and epidemiological evidences strongly indicated that $O$. viverrini infection in the etiology of CCA (Thamavit W, et al., 1978; IARC, 1994; Sripa B, et al., 2007). There has been a strong, positive correlation between opisthorchiasis-associated
CCA and infection with Helicobacter. Infection with $H$. bilis and $H$. hepaticus species can cause biliary cancer (Chang and Parsonnet, 2010).

\section{Helicobacter Species are Causes of Cancer}

Several infectious agents are considered to be causes of cancer in humans. The estimated total of infectionattributable cancer in the year 2002 is 1.9 million cases, or $17.8 \%$ of the global cancer burden. The principal agents are the bacterium H. pylori (5.5\% of all cancer) (Parkin, 2006). Therefore, here is described about Helicobacter species that caused of cancer. Helicobacter is a Gramnegative bacteria possessing a characteristic helical shape and to be a new genus name of Helicobacter (Goodwin et al., 1989). The Helicobacter genus contains about 35 species (Vandamme et al., 1991; Yamaoka 2008; Boyanova, 2011), the most widely known species of the genus is $H$. pylori, which infects up to $50 \%$ of the human population (Yamaoka 2008). Helicobacter species have been reported that found living in the lining of the upper gastrointestinal tract of mammals, birds, and naturally inhabit mammals (except humans) and birds (Ryan and Ray, 2004). They are H. suis, H. baculiformis, $H$. equorum, $H$. hepaticus, $H$. mustelae, $H$. bilis, $H$.felis, $H$. bizzozeronii, $H$. salomonis, $H$. ganmani, $H$. pullorum, $H$. anseris, $H$. brantae, $H$. cinaedi, $H$. canis $H$.fennelliae, $H$. parmetensis, $H$. candensis, $H$.rodentium, H.typhlonicus, $H$. cholecystus, $H$. mesocricetorum $H$. muridarum, $H$. rappini, and H. trogontum (Vandamme et al., 1991; Hua et al., 1999; Yamaoka 2008; Boyanova, L, 2011; MateosMuñoz et al., 2013).

Infection with $H$. pylori causes chronic inflammation and significantly increases the risk of developing duodenal and gastric ulcer disease and gastric cancer. Infection with H. pylori is the strongest known risk factor for gastric cancer, which is the second leading cause of cancerrelated deaths worldwide (Wroblewski et al., 2010). Many studies show the link between $H$. pylori and gastric cancer, mainly gastric cancer developed in approximately $3 \%$ of $H$. pylori-infected patients, compared to none of the uninfected patients. These indicated that $H$. pylori infection significantly increases gastric cancer risk (Uemura et al., 2001). Eradication significantly reduced the presence of premalignant lesions, providing additional evidence that this organism has an effect on early stages of gastric carcinogenesis (Wong et al., 2004; Mera et al., 2005). H. pylori or mixed $H$. pylori and $H$. bilis infection had a significant association between and CCA in patients from northeast Thailand (Boonyanugomol et al., 2012a; 2012c). While, other known Helicobacter species have been reported the associated to cancer in human mainly $H$. hepaticus and H. billis associated to hepatocellular carcinoma (Avenaud et al., 2000; Nilsson et al., 2001; Dore et al., 2002; Coppola et al., 2003; Huang et al., 2004; Ito et al., 2004; Pellicano et al., 2004; Zhang et al., 2004; Rocha et al., 2005; Li et al., 2006; Pellicano et al., 2008). In addition, the association between Helicobacter species and CCA has been reported mainly H. billis (Matsukura et al., 2002; Kobayashi et al., 2005; Bohr et al., 2007), and $H$. ganmani (Bohr et al., 2007). Form above reports indicate 
that Helicobacter species are possible risk of cancer.

\section{Helicobacter spp. Infection in Biliary Tract Cancer Including Cholangiocarcinoma}

Helicobacter spp. have been known to be a causative factor of gastric adenocarcinoma, hepatobiliary disease, and CCA (Bouvard et al., 2009; Zhou et al., 2013; Mateos- Muñoz et al., 2013; Murphy et al., 2014). The Helicobacter spp., such as H.pylori, H. bilis, H. hepaticus, and $H$. cholecystus, have been isolated from the human gallbladder, liver tissue and bile juice and Helicobacter infection has been found to induce chronic active hepatitis, hepatocellular and biliary tract carcinomas in susceptible strains of inbred and genetically engineered mice (Fox et al., 1994; Fox and Lee, 1997; Shomer et al., 1997; Young et al., 2000; Fukuda et al., 2002; Fox et al., 2004; Kobayashi et al., 2005; Abu Al-Soud et al., 2008; Casswall et al., 2010; Kosaka et al., 2010; Boonyanugomol et al., 2012; Fowsantear et al., 2014). It has been suggested that CCA is caused by infection with Helicobacter species (SeguraLópez et al., 2015).

Pradhan and Dali (2004) have been reported that the various histopathological changes in the gallbladder with cholelithiasis and to correlate them with Helicobacter hepaticus infection. A total of 380 cholecystectomy specimens were received and found that among the study group, $43 \%$ cases were found to have chronic cholecystitis, $17 \%$ adenomyosis, $13 \%$ cholesterolosis, $9 \%$ low grade dysplasia, $9 \%$ metaplasia, $7 \%$ malignancy, $1 \%$ carcinoma in situ and 1\%xanthogranulomatous change. All the malignant cases were found to be adenocarcinoma. Out of total 100 cases, $82 \%$ cases were found to have $H$. hepaticus infection. Only one out of 7 malignant cases (14.29\%) was found to be negative for $H$. hepaticus infection. Gallbladder neoplasm was found to be common in Nepal comprising 2.63\%. H. hepaticus infection was found in $82 \%$ of gallbladders and it was found in $87.5 \%$ of malignant cases. Whether H. hepaticus that might be the number one cause for the gallstone formation that ultimately leads to malignancy or itself acts as a risk factor for the pathogenesis of carcinoma gallbladder is yet to be determined. Meanwhile, Fox et al. (2009) reported hamsters naturally infected with $H$. bilis and that aged animals showed chronic hepatitis, hepatic dysplasia, fibrosis, and biliary hyperplasia. Furthermore, Murata et al (2004) has been found $H$. bilis infection in the gallbladder in patients with biliary tract disease. Archival gallbladder specimens from 34 patients (14 males and 20 females) with an average age of $61.4+/-12.2$ years (mean $+/$ - SE) were retrieved, consisting of 11 cases of gallbladder cancer, three of bile duct cancer, 16 of cholecystolithiasis and four of pancreatic cancer. Amplification was observed in 3 of 11 gallbladder cancer cases $(27.2 \%)$ and one of three cases with biliary duct cancer (33.3\%). In total, four of 14 cases with biliary tract cancer were positive for $H$. bilis $(28.6 \%)$. This study suggested that $H$. bilis infection may play a role in biliary tract disease, particularly in biliary tract cancer. During other liver fluke infections, $H$. bilis has been identified in the intrahepatic bile ducts of rats experimentally infected with Fasciola hepatica
(Foster, 1984). Deenonpoe et al (2015) reported the liver fluke $O$. viverrini; an agent caused of CCA, in the biliary tree of the hamsters harbors $H$. pylori and Helicobacterlike bacteria. Accordingly, the association between $O$. viverrini and $H$. pylori may be an obligatory mutualism and possible risk of CCA. H. pylori presented in the biliary tract of patients with hepatolithiasis, while $H$. pylori promotes the formation of stones in the biliary tract. The development of intrahepatic CCA might therefore be linked to the presence of $H$. pylori because of the accelerated activity of cell kinetics in the epithelium of the biliary tract (Kuroki et al., 2002). Roe et al (1999) have been reported that the Helicobacter found in the biliary tract diseases of humans. Helicobacter DNA was detected in $37.5 \%$, and $31.3 \%$ by PCR with urea gene, and $16 \mathrm{~S}$ rRNA, respectively. In addition, Fukuda et al (2002) investigated whether Helicobacter species possess a causative potential for human hepatobiliary disease, especially for hepatobiliary carcinogenesis, and found that Helicobacter DNAs were positive in $10(52.6 \%)$ of the 19 patients with hepatobiliary cancer. The incidence was significantly higher than that $(15.7 \%)$ in the benign cases $(\mathrm{P}=0.03)$. The findings suggest that Helicobacter species may play a role in the pathogenesis of hepatobiliary cancer through an acceleration of biliary cell kinetics.

In addition, Kobayashi et al (2005) have been shown the Helicobacter species in the bile to know their participation in the development of extrahepatic biliary diseases. DNA was extracted from 57 bile samples from 30 patients with benign biliary diseases (cholecystolithiasis and choledochocystolithiasis), 6 malignant biliary diseases (gallbladder cancer and common bile duct cancer), and 21 non-biliary diseases. The presence of Helicobacter genus-, H.pylori-, H. hepaticus-, and H.bilis-specific $16 \mathrm{~S}$ rRNA genes, the $H$. pylori urease A gene, and the $H$.pylori $26 \mathrm{~K}$ protein gene in the bile was determined by PCR and sequencing analysis. Helicobacter genus DNA (shorter amplicons, $400 \mathrm{bp}$ ) was statistically frequently detected in biles from $53 \%(16 / 30)$ and $86 \%(5 / 6)$ of benign and malignant biliary diseases, compared with $9 \%(2 / 21)$ of non-biliary diseases, but longer amplicons (1200 bp) were not detectable in any samples. The H.pylori urease A gene (nested amplicon) was also frequently found in bile, whether benign, malignant, or control, though neither H. pylori $16 \mathrm{~S}$ rRNA nor the $26 \mathrm{~K}$ protein gene was detectable in any bile samples. $H$. bilis-16S rRNA genes were detectable in only two cases. H. hepaticus was not detectable in any samples. DNA fragments of Helicobacter species other than H. pylori, H. hepaticus, and H. bilis are commonly detectable in the bile of patients with extrahepatic biliary diseases, whether benign or malignant, implying that the Helicobacter genus may be directly or indirectly involved in the pathogenesis of these diseases. Abu Al-Soud et al (2008) reported a retrospectively investigated the presence of DNA of Helicobacter species in samples of the cancer and the surrounding tumour-free liver tissues of patients with hepatocellular carcinoma $(n=12)$ and $\mathrm{CCA}(\mathrm{n}=13)$. The patients were from an area with low liver cancer incidence and with low hepatitis $\mathrm{B}$ and $\mathrm{C}$ prevalence. Patients with a benign liver disease $(\mathrm{n}=24)$ were included as controls. PCR assay detected 
Helicobacter DNA in seven of $12(58 \%)$ and eight of 13 (62\%) normal liver tissue specimens from HCC and CC patients, respectively. The study suggested that presence of DNA of Helicobacter species in liver specimens, but not of other common gut bacteria, was associated with human hepatic carcinogenesis. Boonyanugomol et al (2012a; 2012c) reported an association between $H$. pylori and hepatolithiasis or CCA in people in northeast Thailand, a region endemic for opisthorchiasis. In addition, $H$. pylori was found in $66.7 \%, 41.5 \%$ and $25.0 \%$ of the patients in the CCA, cholelithiasis and control groups $(\mathrm{P}<0.05)$, respectively. By comparison, $H$. bilis was found in $14.9 \%$ and $9.4 \%$ of the patients with CCA and cholelithiasis, respectively $(\mathrm{P}>0.05)$, and was absent in the control group. The cagA gene of $H$. pylori was detected in $36.2 \%$ and $9.1 \%$ of the patients with CCA and cholelithiasis, respectively $(\mathrm{P}<0.05)$. Among patients with CCA, cell inflammation and proliferation in the liver and gall bladder were significantly higher among those DNA $H$. pylori positive than negative. These findings suggest that $H$.pylori, especially the cagA-positive strains, may be involved in the pathogenesis of hepatobiliary diseases, especially CCA through enhanced biliary cell inflammation and proliferation (Boonyanugomol et al., 2012a). Boonyanugomol et al (2012c) investigated cag genes; virulent gene related to cancer, and the association of those and the clinical outcomes in hepatobiliary diseases, and found that the vacAs $1 \mathrm{a}+\mathrm{c} / \mathrm{m} 1$, iceA1 and babA2 genes were the most predominant genotypes in both CCA and cholelithiasis patients. The cagA and cagE genes were found significantly more frequently in patients with CCA than those with cholelithiasis ( $\mathrm{P}$ $<0.05)$. The cagA positive samples were the Westerntype cagA and showed that almost all of the detected sequences in Thai hepatobiliary and Thai gastric cancer patients were classified in the same cluster but separated from the cluster of Japan and other countries. The authors suggested that cagA and cagE genes may be associated in the pathogenesis of hepatobiliary diseases, especially of CCA. Besides the bacterial variation, other host factors may be involved in the pathogenesis of hepatobiliary cancer. However, Bohr et al (2007) reported that low prevalence of Helicobacteraceae in gall stone disease and gall bladder carcinoma (GBC) in the German population. Gall-bladder tissue from 99 patients who had undergone cholecystectomy was tested, including 57 cases of gall stone disease (GSD), 20 cases of GBC, and 22 control patients. The presence of Helicobacter spp. was investigated by culture, immunohistochemistry and a group-specific PCR targeting the $16 \mathrm{~S}$ rRNA gene of all currently known Helicobacteraceae. Of the 99 cases investigated, only one patient with GSD was PCR-positive for Helicobacteraceae. For this individual, sequence analysis of the $16 \mathrm{~S}$ rRNA gene showed that it had homology closest to the $16 \mathrm{~S}$ rRNA sequence of H. ganmani. Helicobacteraceae were not detected by culture or immunohistochemistry. The low prevalence of Helicobacteraceae in the gall bladders investigated suggests that Helicobacteraceae do not play a predominant role in the pathogenesis of GSD and GBC in the German population. The low prevalence could be a possible explanation for a relatively low incidence of GBC in the German population, despite the fact that GSD, the major risk factor for $\mathrm{GBC}$, is highly prevalent.

\section{Epidemiological Studies Revealed Helicobacter Species as a Possible Risk of Biliary Tract Cancer Including Cholangiocarcinoma}

Many studies of humans have evaluated the presence of Helicobacter species in biliary tracts of cancer patients versus controls. Base on a meta-analysis study of 10 casecontrol studies contained a cumulative sample size of 205 cases, 115 cases (56\%) were positive for Helicobacter spp. infection, whereas among the 263 controls, 53 (20\%) were positive for Helicobacter spp. infection. Overall meta-analysis favoured a significant association between Helicobacter species infection and CCA (cumulative OR 8.88, 95\% CI 3.67-21.49). Subgroup analysis based on geographic distribution indicated that Helicobacter species infection may serve as a risk factor not only in a region with high CCA incidence (Asia, OR 6.68, 95\% CI 2.29-19.49) but also in low incidence region (Europe, OR 14.90, 95\% CI 4.79-46.35). The reports included suggested that the possible association between Helicobacter species infection and CCA (Xiao et al., 2014). Another metaanalysis of 10 studies published between 2002 and 2011 was reported that the association between Helicobacter pylori, Helicobacter bilis, Helicobacter hepaticus, and Helicobacter ganmani and CCA. A significantly higher pooled infection rate of Helicobacter spp. was observed in the biliary tract cancer group compared with the normal group $(\mathrm{P}=0.0001)$ and the benign biliary disease group, respectively $(\mathrm{P}=0.0001)$. Studies from East Asia and South Asia showed a higher prevalence of Helicobacter spp. in the malignant group. Evidence supporting the higher presence of Helicobacter spp. in the cancer group was obtained using PCR and immunohistochemical analysis of specimens from bile and biliary tissues. This meta-analysis suggests a trend of a higher presence of Helicobacter spp. in patients with biliary tract cancers compared with normal controls or those with benign biliary diseases (Zhou et al 2013).

In addition, a meta-analysis of 5 single group and 10 case control contained the cumulative sample size of cases was 205, of which 115 were positive (56\%) for Helicobacter, while among 263 controls 53 (20\%) were found to be positive for Helicobacter infection. The positivity rate in case control studies was higher than that observed in single group studies. The cumulative odds ratio for the study sample was 8.72 (95\% CI 4.78-15.91) $(\mathrm{Z}=7.07 ; \mathrm{p}<0.00001)$. There is enough evidence to suggest a possible role of Helicobacter species in hepatobiliary tract cancers. However, the results from different regions of the world differ. Studies also differ on method of Helicobacter detection, subsite of cancer with in the hepatobiliary tract and choice of controls thus introducing heterogeneity. The authors suggest that further case control studies with larger sample size are required to settle the question (Pandey and Shukla, 2009).

Meanwhile, case-control studies have been published mainly, Segura-López et al, (2015) reported that 44/103 
Table 1. Possible Risk of Helicobacter Species and Bile Duct Malignancy

\begin{tabular}{|c|c|c|c|c|}
\hline $\begin{array}{l}\text { Type of bile duct } \\
\text { malignancy }\end{array}$ & $\begin{array}{l}\text { Helicobacter } \\
\text { species }\end{array}$ & $\begin{array}{l}\text { Increased } \\
\text { risk }\end{array}$ & $\begin{array}{l}\text { Number of } \\
\text { recruited studies }\end{array}$ & References \\
\hline Extrahepatic CCA & H. bilis & $2.83(1.49,5.32) \mathrm{a}$ & $\begin{array}{r}103 \text { cases and } 91 \text { controls } \\
\text { (Case-control study) }\end{array}$ & Segura-López et al, 2015 \\
\hline $\mathrm{CCA}$ & Helicobacter species & $8.88(3.67,21.49) \mathrm{a}$ & $\begin{array}{r}245 \text { cases and } 244 \text { controls } \\
10 \text { case-control studies } \\
\text { (Meta-analysis) }\end{array}$ & Xiao et al., 2014 \\
\hline Intrahepatic CCA & $\begin{array}{l}\text { H. pylori, } \\
\mathrm{H} \text { bilis }\end{array}$ & $744(2.19,25.28) \mathrm{a}$ & 149 cases and 20 controls & Boonyanugomol et al., 2012 \\
\hline Bile duct cancer & $\begin{array}{l}\text { H. pylori, } \\
\text { H. hepaticus }\end{array}$ & $1.69(0.78,3.66) \mathrm{a}$ & 58 cases and 167 controls & Shimoyama et al., 2010 \\
\hline Intrahepatic CCA & $\begin{array}{l}\text { H. pylori, } \\
\text { H. hepaticus, }\end{array}$ & $11.20(2.16,58.13) \mathrm{a}$ & 21 cases and 27 controls & Abu Al-Soud et al., 2008 \\
\hline Common bile duct cancer & Helicobacter species & $47.50(3.55,363.17) \mathrm{a}$ & 11 cases and 23 controls & Kobayashi et al., 2005 \\
\hline Bile duct cancer & H. bilis & $3.86(0.17,87.65) \mathrm{a}$ & 18 cases and 4 controls & Murata et al., 2004 \\
\hline $\mathrm{CCA}$ & H. pylori & $15.36(0.70,338) \mathrm{a}$ & 17 cases and 6 control & Chen and Chen, 2003 \\
\hline Bile duct cancer & H. bilis & $12.00(2.66,54.19) \mathrm{a}$ & 18 cases and 4 controls & Matsukura et al., 2002 \\
\hline $\mathrm{CCA}$ & Helicobacter spp. & $95.67(4.69,1950.42) \mathrm{a}$ & 24 cases and 20 control & Nilsson et al., 2001 \\
\hline
\end{tabular}

a Odds ratio

cases were positive for $H$. bilis, compared with 19/91 controls ( $\mathrm{p}=0.002$; OR 2.83,95\% CI 1.49-5.32), and when analyzed by sub-site, $H$. bilis infection was significantly more associated with cancer in the common bile duct ( $\mathrm{p}=0.0005 ;$ OR $3.56,95 \%$ CI 1.77-7.17). In contrast, $H$. hepaticus infection was not different between cases $(17 / 103)$ and controls $(13 / 91)(\mathrm{p}=0.82$; OR $1.19,95 \%$ CI 0.54-2.60). None of the samples were positive for $\mathrm{S}$. typhi infection. The authors included that infection with $H$. bilis but neither $H$. hepaticus nor S. typhi was significantly associated with ECCA, particularly with tumors located in the common bile duct. Chang et al (2013) evaluate the association between CCA and each medical risk factor in 5,157 incident cases of CCA diagnosed during 2004 to 2008 and 20,628 controls in Taiwan, and found that factors associated with an increased risk of CCA included cholangitis, cholelithiasis, cholecystitis, cirrhosis of liver, alcoholic liver disease, chronic non-alcoholic liver disease, hepatitis $\mathrm{B}$, hepatitis $\mathrm{C}$, diabetes, chronic pancreatitis, inflammatory bowel disease, and peptic ulcer. This study confirms the association between CCA and several less established risk factors, including diabetes, inflammatory bowel disease, hepatitis B, hepatitis $\mathrm{C}$, and peptic ulcer (proxy for the presence of Helicobacter pylori). In addition, Matsukura et al (2002) determine whether malignant diseases of the biliary tract are associated with the presence of $H$. bilis in bile samples obtained from 45 Japanese and 40 Thai patients. Thirteen out of $15(87 \%)$ Japanese and 11 out of 14 (79\%) Thai patients with bile duct or gallbladder cancer tested positive for the presence of $\mathrm{H}$. bilis in their bile. 8 out of $16(50 \%)$ Japanese and 10 out of $26(38 \%)$ Thai patients with gallstone and / or cholecystitis tested positive for $H$. bilis. Only 4 out of 14 (29\%) subjects without biliary disease tested positive for $H$. bilis among the Japanese. Bile duct and gallbladder cancer showed significantly higher positive rates for $H$. bilis than did the non-biliary diseases among the Japanese $(\mathrm{P}<0.01)$ and the odd ratios for bile duct or gallbladder cancer with $H$. bilis in comparison with gallstone and / or cholecystitis were $6.50(95 \%$ CI $1.09-38.63)$ in the Japanese and $5.86(1.31-26.33)$ in the Thai patients. This study suggested that $H$. bilis infection in bile was associated with biliary tract and gallbladder cancers in the highly risk populations of Japanese and Thai. Furthermore, Bulajic et al (2002) reported the H. pylori and the risk of benign and malignant biliary tract disease and found that there was a strong association between the presence of $H$. pylori in the stomach and in the bile $(\mathrm{P}<$ or $=0.01)$. Biliary $H$. pylori was associated with age but not with gender, and it was associated strongly with the clinical diagnosis. Patients with gallstones were 3.5 times as likely to have $H$. pylori in the bile compared with patients in a control group [95\% CI], 0.8-15.8; $\mathrm{P}=0.100)$, and H.pylori was 9.9 times more frequent in patients with biliary tract carcinoma compared with patients in the control group (95\% CI, 1.4$70.5 ; \mathrm{P}=0.022)$. There is a strong association between biliary tract carcinoma and $H$. pylori in bile. Recently, CCA has been suggested to be cause by infection with Helicobacter spp., such as H. bilis, and, H. hepaticus. The pathogenicity of $H$. bilis and $H$. hepaticus has been studied in various animals infected experimentally or naturally, in which Helicobacter infection has been found to cause chronic active hepatitis, hepatocellular and biliary tract carcinoma, typhlocolitis, and lower bowel cancer. These infections can also promote the development of cholesterol gallstones and intrahepatic cholelithiasis, which is another risk factor for CCA. Multiple clinical studies have identified different Helicobacter spp. in the biliary tract, including $H$. pylori, and have associated these infections with the development of benign and malignant biliary diseases (Segura-López et al., 2015). The association of possible risk between Helicobacter spp. and biliary tract malignancy is included in Table 1.

\section{Helicobacter Species are Associated with Possible Increase in Risk of Cholangiocarcinoma}

Sixth studies have been reported that there are CCA types which are associated to infect Helicobacter spp. Type of CCA is included one extrahepatic CCA (SeguraLópez et al, 2015), two intrahepatic CCA (Abu Al-Soud et al., 2008; Boonyanugomol et al., 2012), three CCA 
(Nilsson et al., 2001; Chen and Chen, 2003; Xiao et al., 2014), three bile duct cancer (Matsukura et al., 2002; Murata et al., 2004; Shimoyama et al., 2010), and one common bile duct cancer (Kobayashi et al., 2005). Helicobacter spp. are identified and found that 2 studies could be detected $H$. pylori in specimens (Abu Al-Soud et al., 2008; Shimoyama et al., 2010; Boonyanugomol et al., 2012), followed by $H$. bilis (Matsukura et al., 2002; Murata et al., 2004; Boonyanugomol et al., 2012; SeguraLópez et al, 2015), and H. hepaticus (Chen and Chen, 2003; Abu Al-Soud et al., 2008; Shimoyama et al., 2010) have been reported in each study. This reveals suggested that Helicobacter spp. are associated with possible increase in risk of CCA, particularly $\mathrm{H}$. and $H$. bilis. The association of possible risk between Helicobacter spp. and CCA is included in Table 1.

\section{Conclusion}

Global epidemiological studies have suggested that Helicobactor spp. are possible risk of biliary tract diseases including CCA. The molecular studies from other investigators support the linkage of Helicobacter spp. and CCA. Up to the present, however, the results from different regions, material and method, subsite of cancer, and controls thus introducing heterogeneity, therefore, case control studies with larger sample size are required. The comparison between co-Helicobacter spp.-CCA in the countries with low and high incident of CCA is required to settle the question. Furthermore, clarify the variation and role of Helicobacter species in this CCA, including pathogenesis of CCA through enhanced biliary cell inflammation and proliferation.

\section{References}

Akamatsu N, Sugawara Y, Hashimoto D. (2011). Surgical strategy for bile duct cancer: Advances and current limitations. World J Clin Oncol, 10, 94-107.

Abu Al-Soud W, Stenram U, Ljungh A, et al (2008). DNA of Helicobacter spp. and common gut bacteria in primary liver carcinoma. Dig Liver Dis, 40, 126-31.

Bohr UR, Kuester D, Meyer F, et al (2007). Low prevalence of Helicobacteraceae in gall-stone disease and gall-bladder carcinoma in German population. Clin Microb Infect, 13, 525-31.

Boonyanugomol W, Chomvarin C, Sripa B, et al (2012). Molecular analysis of Helicobacter pylori virulentassociated genes in hepatobiliary patient. HPB (Oxford), 14, 754-63.

Boonyanugomol W, Chomvarin C, Sripa B, et al (2012). Helicobacter pylori in Thai patients with cholangiocarcinoma and its association with biliary inflammation and proliferation. HPB (Oxford), 14, 177-84.

Boonyanugomol W, Chomvarin C, Baik SC, et al (2011). Role of cagA-positive Helicobacter pylori on cell proliferation, apoptosis, and inflammation in biliary cells. Dig Dis Sci, 56, 1682-92.

Boyanova, L (2011). Helicobacter pylori. Caister Academic Press, Norfolk, England.

Bulajic M, Maisonneuve P, Schneider-Brachert W, et al (2002). Helicobacter pylori and the risk of benign and malignant biliary tract disease. Cancer, 95, 1946-53.
Bulajic M, Panic N, Stimec B, et al (2012). PCR in Helicobacter spp. diagnostic in extragastric malignancies of digestive system. Eur J Gastroenterol Hepatol, 24, 117-25.

Casswall TH, Németh A, Nilsson I, et al (2010). Helicobacter species DNA in liver and gastric tissues in children and adolescents with chronic liver disease. Scand $J$ Gastroenterol, 45, 160-7.

Chang AH.; Parsonnet, J. (2010). Role of Bacteria in Oncogenesis. Clin Microb Rev, 23, 837-7.

Chang JS, Tsai CR, Chen LT (2013). Medical risk factors associated with cholangiocarcinoma in Taiwan: a populationbased case-control study. PLoS One, 8, 69981.

Chen H, Chen Y (2003). Helicobacter-specific 16S ribosomal DNA identified from patients with cholangiocarcinoma. Chin J Gen Surg, 12, 27-9.

Coppola N, De Stefano G, Marrocco C, et al (2003). Helicobacter spp. and liver diseases. Infez Med, 11, 201-7.

Dayton M, Longmire W, Tompkins R (1983). Caroli's Disease: a premalignant condition?. Am J Surg, 145, 41-8.

Deenonpoe R, Chomvarin C, Pairojkul C, et al (2015). The carcinogenic liver fluke Opisthorchis viverrini is a reservoir for species of Helicobacter. Asian Pac J Cancer Prev, 16, 1751-8.

Dore MP, Realdi G, Mura D, et al (2002). Helicobacter infection in patients with $\mathrm{HCV}$-related chronic hepatitis, cirrhosis, and hepatocellular carcinoma. Dig Dis Sci, 47, 1638-43.

Donato F, Gelatti U, Tagger A, et al (2001). Intrahepatic cholangiocarcinoma and hepatitis $\mathrm{C}$ and $\mathrm{B}$ virus infection, alcohol intake, and hepatolithiasis: a case-control study in Italy. Cancer Causes Control, 12, 959-64.

Fox JG, Dewhirst FE, Tully JG, et al (1994). Helicobacter hepaticus sp. nov., a microaerophilic bacterium isolated from livers and intestinal mucosal scrapings from mice. $J$ Clin Microbiol, 32, 1238-45.

Fox JG, Lee A (1997). The role of Helicobacter species in newly recognized gastrointestinal tract diseases of animals. $L a b$ Anim Sci, 47, 222-55.

Fox JG, Rogers AB, Whary MT, (2004). Helicobacter bilisassociated hepatitis in outbred mice. Comp Med, 54, 571-7.

Fox JG, Shen Z, Muthupalani S, et al (2009). Chronic hepatitis, hepatic dysplasia, fibrosis, and biliary hyperplasia in hamsters naturally infected with a novel Helicobacter classified in the H. bilis cluster. J Clin Microbiol, 47, 3673-81.

Foster JR (1984). Bacterial infection of the common bile duct in chronic fascioliasis in the rat. J Comp Pathol,94, 175-81.

Fowsantear W, Argo E, Pattinson C, et al (2014). Comparative proteomics of Helicobacter species: the discrimination of gastric and enterohepatic Helicobacter species. J Proteomics, 97, 245-5.

Fukuda K, Kuroki T, Tajima Y, et al (2002). Comparative analysis of Helicobacter DNAs and biliary pathology in patients with and without hepatobiliary cancer. Carcinogenesis, 23, 1927-31.

Goodwin CS, Armstrong JA, Chilvers T, et al (1989). Transfer of Campylobacter pylori and Campylobacter mustelae to Helicobacter gen. nov. as Helicobacter pylori comb. nov. and Helicobacter mustelae comb. nov., respectively. Int $J$ Syst Bacteriol, 39, 397-405.

Green A, Uttaravichien T, Bhudhisawasdi V, et al. (1991). Cholangiocarcinoma in northeast Thailand. A hospital-based study. Trop Geogr Med, 43, 193-8.

Herrold KM (1967). Histogenesis of malignant liver tumors induced by dimethylnitrosamine. An experimental study in Syrian hamsters. J Natl Cancer Inst, 39, 1099-111.

Hua JS, Zheng PY, Ho B (1999). Species differentiation and identification in the genus of helicobacter. World $J$ 
Gastroenterol, 5, 7-9.

Huang Y, Fan XG, Zhou JH (2004). Immunohistochemistry of Helicobacter pylori in primary liver carcinoma tissues. Zhong Nan Da Xue Xue Bao Yi Xue Ban, 29, 15-7.

IARC. (1994). Infection with liver flukes (Opisthorchis viverrini, Opisthorchis felineus and Clonrochis sinensis). IARC Monogr Eval Carcinog Risks of Hum, 61, 121-75.

Ito K, Nakamura M, Toda G, et al (2004). Potential role of Helicobacter pylori in hepatocarcinogenesis. Int $\mathrm{J} \mathrm{Mol}$ Med, 13, 221-7.

Jing W, Jin G, Zhou X, et al (2012). Diabetes mellitus and increased risk of cholangiocarcinoma: a meta-analysis. Eur J Cancer Prev, 21, 24-31.

Kobayashi T, Harada K, Miwa K, et al (2005). Helicobacter genus DNA fragments are commonly detectable in bile from patients with extrahepatic biliar diseases and associated with their pathogenesis. Dig Dis Sci, 39, 862-7.

Kosaka T, Tajima Y, Kuroki T, et al (2010). Helicobacter bilis colonization of the biliary system in patients with pancreaticobiliary maljunction. Br J Surg, 97, 544-9.

Kuroki T, Fukuda K, Yamanouchi K, (2002). Helicobacter pylori accelerates the biliary epithelial cell proliferation activity in hepatolithiasis. Hepatogastroenterol, 49, 648-51.

Landis S, Murray T, Bolden S, et al(1998). Cancer statistics, 1998. CA Cancer J Clin, 48, 6-29.

Lee S, Kim M, Lee S, et al (2004). Clinicopathologic review of 58 patients with biliary papillomatosis. Cancer, 100, 783-93.

Lee C, Wu C, Chen G (2002). What is the impact of coexistence of hepatolithiasis on cholangiocarcinoma?.J Gastroenterol Hepatol, 17, 1015-20.

Li N, Zhang SH, Xuan SY, et al (2006). Study on Helicobacter infection in liver tissue from hepatocellular carcinoma. Zhonghua Liusingbingxue Zazhi, 27, 894-6.

Lipsett P, Pitt H, Colombani P, et al (1994). Choledochal cyst disease. A changing pattern of presentation. Ann Surg, 220, 644-52.

Maksimova GA, Zhukova NA, Kashina EV, et al (2015). Role of Opisthorchis felineus on induction of bile duct cancer. Parazitologiia, 49, 3-11.

Mateos-Muñoz B, Pérez-de-la-Serna J, Ruiz-de-León A, et al (2013). Enterohepatic Helicobacter other than Helicobacter pylori. Rev Esp Enferm Dig, 105, 477-84.

Matsukura N, Yokomuro S, Yamada S, et al (2002). Association between Helicobacter bilis in bile and biliary tract malignancies: $H$. bilis in bile from Japanese and Thai patients with benign and malignant diseases in the biliary tract. $J p n$ J Cancer Res, 93, 842-7.

Mecklin J, Järvinen H, Virolainen M (1992). The association between cholangiocarcinoma and hereditary nonpolyposis colorectal carcinoma. Cancer, 69, 1112-4.

Migasena P, Changbumrung S (1974). The role of nitrosamines in the cause of primary carcinoma.J Med Assoc Thai, 57, 175-8.

Migasena P, Reaunsuwan W, Changbumrung S (1980). Nitrates and nitrites in local Thai preserved protein foods. J Med Assoc Thai, 63, 500-5.

Mera R, Fontham ET, Bravo LE, et al (2005). Long term follow up of patients treated for Helicobacter pylori infection. Gut, 54, 1536-40.

Mitacek EJ, Brunnemann KD, Hoffmann D, et al (1999). Volatile nitrosamines and tobacco- specific nitrosamines in the smoke of Thai cigarettes: a risk factor for lung cancer and a suspected risk factor for liver cancer in Thailand. Carcinogenesis, 20, 133-7.

Murata H, Tsuji S, Tsuji M, et al (2004). Helicobacter bilis infection in biliary tract cancer. Aliment Pharmacol Ther, 20, $90-4$.

Nilsson HO, Mulchandani R, Tranberg KG, et al (2001).
Helicobacter species identified in liver from patients with cholangiocarcinoma and hepatocellular carcinoma. Gastroenterol, 120, 323-4.

Oh JK, Weiderpass E (2014). Infection and Cancer: Global Distribution and Burden of Diseases. Ann Glob Health, 80, 384-92.

Pandey M, Shukla M (2009). Helicobacter species are associated with possible increase in risk of hepatobiliary tract cancers. Surg Oncol, 18, 51-6.

Parkin DM (2006). The global health burden of infectionassociated cancers in the year 2002. Int J Cancer, 118, 3030-44.

Palmer WC, Patel T (2012). Are common factors involved in the pathogenesis of primary liver cancers? A meta-analysis of risk factors for intrahepatic cholangiocarcinoma. J Hepatol, 57, 69-76.

Park J, Oh S, Kim S, et al (2005). Single-agent gemcitabine in the treatment of advanced biliary tract cancers: a phase II study. Jpn J Clin Oncol, 35, 68-73.

Patel T (2002). Worldwide trends in mortality from biliary tract malignancies. BMC Cancer, 2, 10.

Pellicano R, Mazzaferro V, Grigioni WF, et al (2004). Helicobacter species sequences in liver samples from patients with and without hepatocellular carcinoma. World J Gastroenterol, 10, 598-601.

Pellicano R, Méard A, Rizzetto M, et al (2008). Helicobacter species and liver diseases: Association or causation?. Lancet Infect Dis, 8, 254-60.

Philip P, Mahoney M, Allmer C, et al (2006). Phase II study of erlotinib in patients with advanced biliary cancer. J Clin Oncol, 24, 3069-74.

Pradhan SB, Dali S (2004). Relation between gallbladder neoplasm and Helicobacter hepaticus infection. Kathmandu Univ Med J, 2, 331-5.

Ryan KJ, Ray CG (2004). Sherris Medical Microbiology (4th ed.). McGraw Hill.

Roe IH, Kim JT, Lee HS, et al (1999). Detection of Helicobacter DNA in bile from bile duct diseases. J Korean Med Sci, 14, 182-6.

Ren HB, Yu T, Liu C, et al (2011). Diabetes mellitus and increased risk of biliary tract cancer: systematic review and meta-analysis. Cancer Causes Control, 22, 837-47.

Rocha M, Avenaud P, Ménard A, et al (2005). Association of Helicobacter species with hepatitis $\mathrm{C}$ cirrhosis with or without hepatocellular carcinoma. Gut, 54, 396-401.

Rosen CB, Heimbach JK, Gores GJ (2008). Surgery for cholangiocarcinoma: the role of liver transplantation. Official J Inter Hepato Pancreato Biliary Assoc, 10, 186-9.

Saengboonmee C, Seubwai W, Wongkham C, et al (2015). Diabetes mellitus: Possible risk and promoting factors of cholangiocarcinoma Association of diabetes mellitus and cholangiocarcinoma. Cancer Epidemiol, 39, 274-8.

Sahani D, Prasad S, Tannabe K, et al (2003). Thorotrast-induced cholangiocarcinoma: case report. Abdom Imaging, 28, $72-4$.

Segura-López FK, Avilés-Jiménez F, Güitrón-Cantú A, et al (2015). Infection with Helicobacter bilis but not Helicobacter hepaticus was Associated with Extrahepatic Cholangiocarcinoma. Helicobacter, 20, 223-30.

Segura-López FK, Güitrón-Cantú A, Torres J (2015). Association between Helicobacter spp. infections and hepatobiliary malignancies: A review. World J Gastroenterol, 21, 1414-23.

Shaib Y, El-Serag H, Davila J, (2005). Risk factors of intrahepatic cholangiocarcinoma in the United States: a case-control study. Gastroenterology, 128, 620-6.

Shin HR, Oh JK, Masuyer E, et al. (2010). Epidemiology of cholangiocarcinoma: an update focusing on risk factors. Cancer Sci, 101, 579-85. 
Shimoyama T, Takahashi R, Abe D, et al (2010). Serological analysis of Helicobacter hepaticus infection in patients with biliary and pan- creatic diseases. J Gastroenterol Hepatol, 25, 86-9.

Shomer NH, Dangler CA, Schrenzel MD, et al (1997). Helicobacter bilis-induced inflammatory bowel disease in scid mice with defined flora. Infect Immun, 65, 4858-64.

Sorensen H, Friis S, Olsen J, et al (1998). Risk of liver and other types of cancer in patients with cirrhosis: a nationwide cohort study in Denmark. Hepatology, 28, 921-5.

Sripa B, Yongvanit P, Pairojkul C (2005). Etiology and pathogenesis of cholangiocarcinoma: introduction to the association with liver fluke infection. Srinagarind Med $J$, 20, 123-34

Sripa B, Kaewkes S, Sithithaworn P, Met al. (2007). Liver fluke induces cholangiocarcinoma. PLoS Med, 4, 201.

Sripa B, Kaewkes S, Intapan PM, et al (2010). Food-borne trematodiases in Southeast Asia epidemiology, pathology, clinical manifestation and control. Adv Parasitol, 72, 305350 .

Su C, Shyr Y, Lui W, et al (1997). Hepatolithiasis associated with cholangiocarcinoma. Br J Surg, 84, 969-73.

Thamavit W, Bhamarapravati N, Sahaphong S, et al. (1978). Effects of dimethylnitrosamine on induction of cholangiocarcinoma in Opisthorchis viverrini-infected Syrian golden hamsters. Cancer Res, 38, 4634-9.

Thunyaharn N, Promthet S, Wiangnon SS, et al (2013). Survival of cholangiocarcinoma patients in northeastern Thailand after supportive treatment. Asian Pac J Cancer Prev, 14, 7029-32.

Uemura N., Okamoto S, Yamamoto S, et al (2001). Helicobacter pylori infection and the development of gastric cancer. $N$ Engl J Med, 345, 784-9.

Vandamme P, Falsen E, Rossaq R, et al (1991). Revision of Campylobacter, Helicobacter, and Wolinella taxonomy: emendation of generic descriptions and proposal of Arcobacter gen. nov. Int J Syst Bacteriol, 41, 88-103.

Watanapa P, Watanapa W (2002). Liver fluke-associated cholangiocarcinoma. Br J Surg, 89, 962-70.

Wroblewski LE, Peek RM, Wilson KT (2010). Helicobacter pylori and gastric cancer: factors that modulate disease risk. Clin Microbiol Rev, 23, 713-39.

Xiao M, Gao Y, Wang Y (2014). Helicobacter species infection may be associated with cholangiocarcinoma: a metaanalysis. Int J Clin Pract, 68, 262-70.

Yamaoka Y (2008). Helicobacter pylori: molecular genetics and cellular biology. caister academic press, Norfolk, England.

Yeo CJ, Pitt HA, Cameron JL (1990). Cholangiocarcinoma. Surg Clin North Am, 70, 1429-47.

Young VB, Knox KA, Schauer DB (2000). Cytolethal distending toxin sequence and activity in the enterohepatic pathogen Helicobacter hepaticus. Infect Immun, 68, 184-91.

Zhang LF, Zhao HX (2013). Diabetes mellitus and increased risk of extrahepatic cholangiocarcinoma: a meta-analysis. Hepatogastroenterol, 60, 684-7.

Zhang SQ, Bao Y, Zu MH (2004). The correlation between Helicobacter infection and hepatocellular carcinoma. Zhongguo Zhongliu Linchuang, 31, 761-4.

Zhou D, Wang JD, Weng MZ, et al (2013). Infections of Helicobacter spp. in the biliary system are associated with biliary tract cancer: a meta-analysis. Eur J Gastroenterol Hepatol, 25, 447-54.

Zhu A, Lauwers G, Tanabe K (2004). Cholangiocarcinoma in association with Thorotrast exposure. J Hepatobiliary Pancreat Surg, 11, 430-3. 